\title{
Isoniazid Induced Generalized Lichenoid Drug Eruption: An Unusual Offender
}

\author{
Pratima Singh ${ }^{1, \star}$, Deepak Nathiya', Sonal Jain², Preeti Raj', Supriya Suman', Balvir Singh Tomar ${ }^{3}$ \\ ${ }^{1}$ Department of Pharmacy Practice, Institute of Pharmacy, NIMS University, Jaipur, Rajasthan, INDIA. \\ ${ }^{2}$ Department of Dermatology, Venereology and Leprosy, NIMS University, Jaipur, Rajasthan, INDIA. \\ ${ }^{3}$ Department of Gastroenterology and Hepatology, NIMS University, Jaipur, Rajasthan, INDIA.
}

\begin{abstract}
Introduction: Isoniazid also known as isonicotinic acid hydrazide is first line drug in anti-tubercular regimen. We report the case of lichenoid drug eruption due to this drug. Case-Report: A Sixty four-year old man received treatment for transverse myelitis with pulmonary TB. After almost four months of initiation of regimen he developed viloaceous lesions first from back and gradually involving $B / L$ extremities. A skin punch biopsy is indicative of drug-induced lichenoid drug eruption. Isoniazid dechallenge and rechallenge confirmed the diagnosis of "Isoniazid induced lichenoid Drug eruption". Discussion: Incidence of isoniazid induced CADR is 0.98\%. Diagnosis decisionmaking should be on the basis of critical analysis of case. Role of Pharmacovigilance is crucial to understand quality and frequency of adverse drug reactions
\end{abstract}

Key words: Lichenoid drug eruption, Isoniazid, Tuberculosis, Cutaneous adverse drug eruption, ATT.

\section{INTRODUCTION}

India bears the largest proportion of tuberculosis cases characterizing it as public health concern. ${ }^{1}$ Anti-tubercular therapy mainly first-line drugs plays a crucial role in the management of an airborne infectious disease. Lichenoid drug eruption resembles with clinical features lichen planus which can cause symptomatic rash to life-threatening condition. ${ }^{2}$ Lichenoid drug eruptionshows type IV hypersensitivity, TNF- $\alpha$-triggering keratinocyte apoptosis through CD8+ cytotoxic T cells. ${ }^{3}$ Characterized by distinctive uniform eruptions, erythematous or violaceous caling papules and plaques with classic sites resembling lichen planus on the trunk and extremities sparing wrist areas. The relation between offending drug and lesions are established with the time duration between initiation of the offending drug and the occurrence of the cutaneous lesions varies from several weeks to a year or more and depends upon the classification of drug, dose, dosage from, host reaction and concurrent drugs. ${ }^{4} \mathrm{LDE}$ accounts for total $1 \%$ cases from many class of drugs. ${ }^{5}$ Isoniazid also known as isonicotinic acid hydrazide induced CADR (Cutaneous adverse drug eruption) is rare with incidence $0.98 \% .6,7$ Lichenoid drug reactions due to isoniazid are rare, hence we are reporting this case.

\section{CASE REPORT}

A 63- year old male presented to Dermatology OPD of National Institute of Medical Sciences Hospital, Jaipur, Rajasthan, India (A Tertiary care super specialty Hospital) with a generalized itchy scaly rash from 2 weeks. The lesions first began from back slowly and gradually involving B/L extremities, sparing the face (Figure 1). History revealed him to be a case of transverse myelitis with Pulmonary TB under ATT for the past 4 months.

His physical examination was notable for multiple violaceous papules and plaques of varying size, coaxing at places with surface. Besides, it was scaly, polymorphic, confluent and erythematous sparing oral mucosa. Hematological studies were suggestive of a low level of lymphocytes (5\%) and mild
DOI: 10.5530/ijopp.13.3.44

Address for correspondence: Pratima Singh Department of Pharmacy Practice, Institute of Pharmacy, NIMS University, Jaipur, Rajasthan, INDIA. Phone no: +919660864780 Email Id: pratima9525@gmail. com

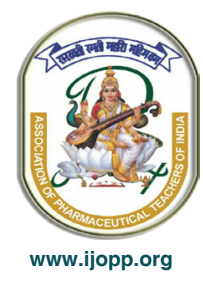




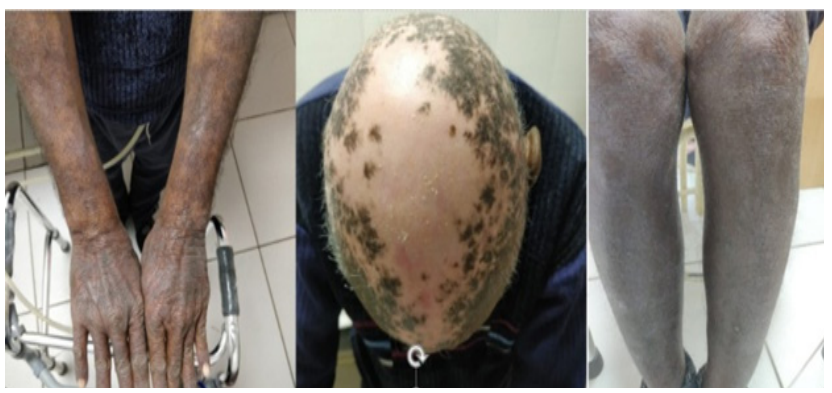

Figure 1: Multiple, extensive violaceous papules and plaques.

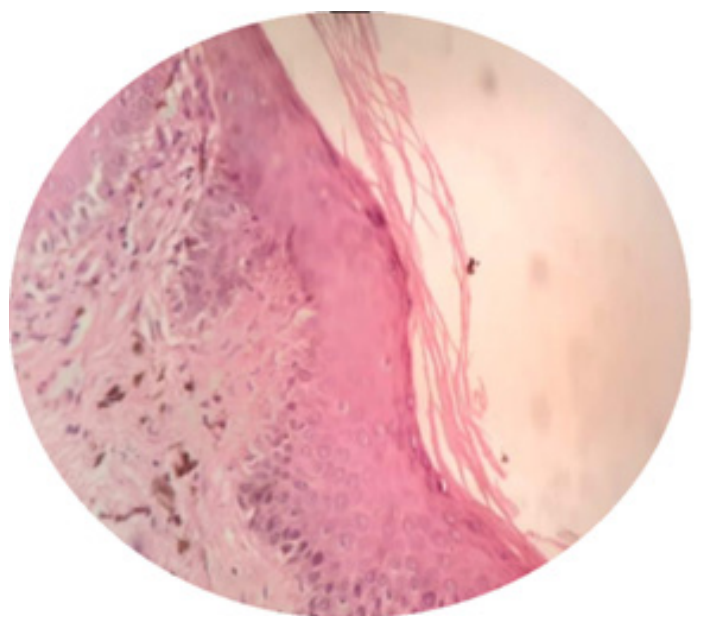

Figure 2: Punch biopsy specimen showing epidermis with focal thinning and hydropic degeneration, epidermis shows mild infiltration of inflammatory cells and melanin containing macrophages with no eosinophils.

\begin{tabular}{|c|c|c|}
\hline Parameter & Normal Value* & Observed value \\
\hline Hemoglobin & $13-18 \mathrm{~g} / \mathrm{dl}$ & 14.7 \\
\hline Neutrophils & $45-75 \%$ & 92 \\
\hline TLC & 4.5-12.5 ths/ul & 13.2ths/ul \\
\hline Lymphocytes & $25-45 \%$ & 05 \\
\hline Monocytes & $2-8$ & 03 \\
\hline Platelet Count & $150-450 \times 103 / u L$ & 280 \\
\hline Serum Urea & $15-45 \mathrm{mg} / \mathrm{dl}$ & 20.8 \\
\hline Serum Creatinine & $0.6-1.6 \mathrm{mg} / \mathrm{dl}$ & 0.84 \\
\hline Total cholesterol & $130-200 \mathrm{mg} / \mathrm{dl}$ & 213.0 \\
\hline Triglycerides & $90-150 \mathrm{mg} / \mathrm{dl}$ & 130.0 \\
\hline Bilirubin Total & $0.2-1.2 \mathrm{mg} / \mathrm{dl}$ & 0.60 \\
\hline Bilirubin Direct & $0.0-0.25 \mathrm{mg} / \mathrm{dl}$ & 0.10 \\
\hline Bilirubin Indirect & $0.2-1.0 \mathrm{mg} / \mathrm{dl}$ & 0.50 \\
\hline SGOT(AST) & $10-50 \mathrm{U} / \mathrm{L}$ & 32.0 \\
\hline SGPT(ALT) & $10-40 \mathrm{U} / \mathrm{L}$ & 35.0 \\
\hline $\begin{array}{c}\text { Alkaline } \\
\text { Phosphatase }\end{array}$ & $80-300 \mathrm{u} / \mathrm{l}$ & 248.0 \\
\hline Total Protein & $6.0-8.0 \mathrm{~g} / \mathrm{dl}$ & 5.6 \\
\hline Albumin & $3.5-5.2 \mathrm{~g} / \mathrm{dl}$ & 3.3 \\
\hline Globulin & $2.3-3.6 \mathrm{~g} / \mathrm{dl}$ & 2.3 \\
\hline
\end{tabular}

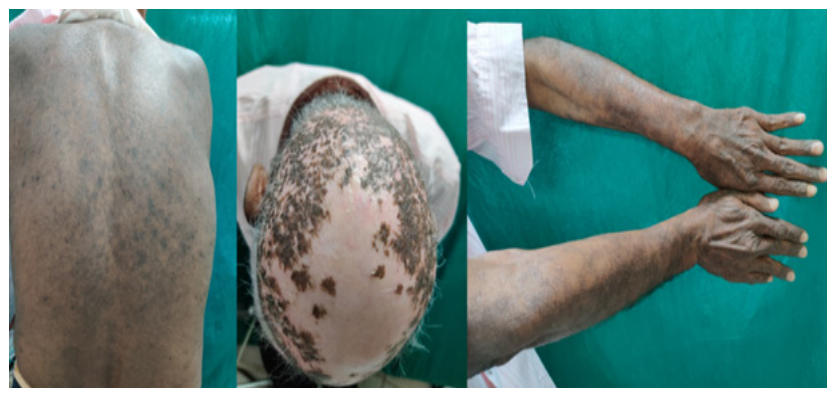

Figure 3: Improvement after dechallenge and management of eruption.

Table 2: Microbiological and Serology analysis report of Patient with Isoniazid Induces Lichenoid Drug Eruptions. ${ }^{15}$

\begin{tabular}{cc}
\hline Investigations & Result \\
\hline HCV & Negative \\
HIV Test & Negative \\
HBsAg & Negative \\
\hline
\end{tabular}

leukocytosis. Serological tests, urinalysis, renal function test and lipid profile were in normal limits. (Table 1,2). ${ }^{15}$ The ultrasonography of whole abdomen reports normal findings with no ascites and pleural effusion. Skin punch biopsy showed epidermis with focal thinning and hydropic degeneration of the basal layer. Underlying dermis shows mild infiltration of inflammatory cells and melanin-containing macrophages (Figure 2). Overall, histopathological features are suggestive of lichen planus.

Anti-tubercular drugs were stopped and started with ofloxacin, streptomycin and ethionamide.

After two weeks of cessation from anti-tubercular regimen, on the interval of one week individual drugs were reintroduced in the following manner starting with ethambutol, succeeding with pyrazinamide, then rifampicin and isoniazid consecutively. Before isoniazid rechallenge, he didn't develop any skin lesions. However, he rapidly developed similar lesions with intense itching after reintroducing isoniazid. The diagnosis of 'Isoniazid induced lichenoid drug eruption' was made.

Patient was given oral prednisolone at dose of $30 \mathrm{mg}$ which was gradually tapered along with topical potent steroids. The lesions subsided in 3 weeks with hyperpigmentation and the patient was put on an alternative regimen of antitubercular drug excluding isoniazid'.(Figure 3)

The causality assessment for relationship possibility between drug and occurrence of event was using Naranjo scale with the score-7 (Certain) for isoniazid. On Hartwig and Siegel Scale the severity of adverse drug reaction was observed 'moderate' (Level-3).

Indian Journal of Pharmacy Practice, Vol 13, Issue 3, Jul-Sep, 2020 


\section{DISCUSSION}

The diagnosis of isoniazid drug-induced lichenoid eruption was made based on patient history, the morphology of skin lesions and the temporal relationship of cessation of regimen further rechallenge leading to recurrence of lesions. Lichenoid drug eruption is infrequent and uncommon indicative of INH induced cases of $0.98 \%$ incidence for cutaneous adverse reactions. ${ }^{7}$ Interruption in the anti-tubercular regimen leads to treatment failure, occurrence of drug resistance, or relapse. Other Studies have also reported association of lichenoid drug eruption in association with isoniazid. ${ }^{8}$ Differential diagnosis also includes idiopathic lichen planus unlike the involvement of flexural surfaces, lichenoid drug eruption features of violaceous coaxing plaques involving Bilateral extremities. ${ }^{5,9}$ In contrast to Lichen planus, lesion of LDE are wider in size, lacks monomorphic appearance and more prone to be eczematous. LP includes mucosal surface, genitalia and presents Wickham's striae. Various drugs cause lichenoid drug eruption includes thiazides, antimalarials, diuretics, beta blockers, ACE inhibitors, gold salts, penicillamine and also lipid-lowering drugs i.e statins and fibrates. ${ }^{10}$ The slow inactivation of INH due to an aberrant isoniazid acetylase enzyme in the liver may role a role in causing lichenoid eruption. ${ }^{11}$ The pathogenesis of lichenoid drug eruption is not clear; yet inflammatory autoimmune attack by $\mathrm{T}$ cells and cytokines interactions on the epidermis seems to be the initial pathological occurrence. $^{12}$

Cutaneous adverse reactions occur in weeks to over a year after the first administration of offender drug. In our case, reaction occurs after almost 4 months of therapy. Diagnosis should be done based on arrant clinical and medication history, physical examination and histopathological findings. Resolution of lesions after the withdrawal of offending drug and remission after reintroduction is a susceptive test for confirming the culprit drug, but it does not always reproduce the skin reaction, though the process is time-consuming for when multiple drugs are suspect and contraindicated is severe reactions. ${ }^{6,7}$

Lichenoid drug eruptions are self-limiting after withdrawal of offending drug. In some patients lesions reoccur even with stopping the offending drug, in such cases management is required.

Besides, other scenarios impacting quality of life or other co-morbid conditions further treatment can be added. Topical corticosteroids can be used in first such as clobetasol, if relief is not obtained as in the presenting case, oral corticosteroids (prednisone) can be indicated. ${ }^{14}$ Adverse drug reaction reporting was done from our PvPI centre. Pharmacovigilance role is consequential in the reporting of low incidence adverse drug reactions to understand the safety and develop risk management plans. Also, enhance knowledge regarding the quality and frequency of adverse drug reactions

\section{Ethical approval}

Informed consent was obtained from our patient in accordance to institutional guidelines.

\section{CONFLICT OF INTEREST}

The authors declare no Conflicts of interest.

\section{ABBREVIATIONS}

LDE: Lichenoid drug eruption; CADR: Cutaneous adverse drug reactions; ATT: Anti-tubercular treatment; LP: Lichen Planus.

\section{REFERENCES}

1. World Health Organization. Global Tuberculosis Report. 2016. [Updated 2017 Dec 20 ; cited 2020 Apr 29] Available from: http://www.who.int/tb/publications/ global_report/gtbr2016_executive_summary.pdf

2. Ammar AM, Pritchard S, Reichenberg J. A review of cutaneous drug eruptions. Clin Geriatr Med. 2013;29(2):527-45. doi:10.1016/j.cger.2013.01.008

3. Sugermann P, Savage N, Seymour G, Walsh L. Is there a role for tumor necrosis factor-alpha (TNF-alpha) in oral lichen planus?. Journal of Oral Pathology and Medicine. 1996;25(5):219-24.

4. Asarch A, Gottlieb A, Lee J, Masterpol K, Scheinman P, Stadecker M, et al. Lichen planus-like eruptions: An emerging side effect of tumor necrosis factor-a antagonists. Journal of the American Academy of Dermatology. 2009;61(1):10411.

5. Halevy S, Shai A. Lichenoid drug eruptions. Journal of the American Academy of Dermatology. 1993;29(2):249-55.

6. Arndt K. Rates of Cutaneous Reactions to Drugs. JAMA. 1976;235(9):918.

7. Sharma PK, Gautam RK, Bhardwaj M, Kar HK. Isonicotinic acid hydrazide induced anagen effluvium and associated lichenoid eruption. The Journal of Dermatology. 2001;28(12):737-41.

8. Tan WC, Ong CK, Kang SC, Razak MA. Two years review of cutaneous adverse drug reaction from first line anti-tuberculous drugs. Medical Journal of Malaysia. 2007;62(2):143-6.

9. Chakraborty PP, Mondal PC. INH induced lichenoid eruptions. J Assoc Physicians India. 2012;60:45

10. Grossman ME, Warren K, Mady A, Satra KH. Lichenoid eruption associated with ethambutol. J Am Acad Dermatol. 1995;33(4):675-6. doi: 10.1016/01909622(95)91307-6

11. Yawalkar N, Pichler WJ. Mechanisms of cutaneous drug reactions (in German). J Dtsch Dermatol Ges. 2004;2(12):1013-23.

12. Brauer J, Votava HJ, Meehan S, Soter NA. Lichenoid drug eruption. Dermatol Online J. 2009;15(8):13. Published 2009 Aug

13. Arndt K. Rates of Cutaneous Reactions to Drugs. JAMA. 1976;235(9):918.

14. Cribier B, Frances C, Chosidow O. Treatment of lichen planus: An evidencebased medicine analysis of efficacy. Arch Dermatol. 1998;134(12):152-30.

15. Mohan, Harsh. A Textbook of Pathology. India. Jaypee Brothers Medical Publishers Pvt. Limited, 2014. ISBN 9351523691. 